\title{
Acute Poisoning via Consumption of "Natural Max Slimming" Capsule with Complications (Hyperpigmentation and Lower Extremity Edema)
}

\author{
Fazel Goudarzi, ${ }^{1}$ Nahid Najafi, ${ }^{2,}$ Negar Azarpira, ${ }^{3}$ Nasim Tavakoli, ${ }^{1}$ and Zohre Najafi ${ }^{4}$ \\ ${ }^{1}$ Ali Asghar Hospital, Shiraz University of Medical Sciences, Shiraz, Iran \\ ${ }^{2}$ Department of Toxicology and Pharmacology, Student Research Committee, School of Pharmacy, Shiraz University of Medical Sciences, Shiraz, Iran \\ ${ }^{3}$ Organ Transplant Research Center, Namazi Hospital, Shiraz University of Medical Sciences, Shiraz, Iran \\ ${ }^{4}$ Department of Veterinary Medicine, Shahid Chamran University, Ahvaz, Iran \\ "Corresponding author: Nahid Najafi, Department of Toxicology and Pharmacology, Student Research Committee, School of Pharmacy, Shiraz University of Medical Sciences, \\ Shiraz, Iran. Tel: +98-9390695265, E-mail: najafi_n@sums.ac.ir
}

Received 2015 November 11; Revised 2016 July 18; Accepted 2016 August 03.

\begin{abstract}
There are verities of none-prescribed slimming products available in the markets which are not approved by the FDA. Hence, different kind of problem has accrued and many complications are unresolved, and an individual healthy is exposed to risks. In this case, although all measures were taken to treat the patient but recovery was extremely slow and it lasted several weeks.
\end{abstract}

Keywords: Case Report, Herbal Product, Natural Max Slimming, Acute Poisoning, Hyperpigmentation

\section{Introduction}

A wide variety of illicit, weight-reducing agents has been discovered in proprietary slimming products that are readily available to the public. Most importantly, ingestion of these products may lead to significant toxicities and even mortality $(1,2)$.

The presence of synthetic adulterants in herbal product poses a serious health risk to consumers. The resulting clinical consequences may be serious and sometimes life threatening.

Consumers have been warned by the food and drug administration, neither to buy nor make use of natural max slimming, a product developed for weight loss. It was established by the FDA laboratory analysis that natural max slimming contains sildenafil, fluoxetine and sibutramine (3).

Sibutramine was removed from the market in October $2010(4,5)$ for safety reasons such as increase blood pressure and/or pulse rate with a significant risk for patients with a history of coronary artery disease, congestive heart failure, arrhythmias, or stroke (6).

Recently, sibutramine was discovered in herbal product developed for weight loss (7), and in humans, sibutramine rapidly demethylates to its pharmacologically active metabolites, N-desmethylsibutramine and $\mathrm{N}$-desmethylsibutramine (8). It has structural similarities to amphetamine and is a serotonin-norepinephrine reuptake inhibitor (9). After oral consumption of Natural
Max Slimming capsules, sibutramine is fast absorbed and is subjected to marked first pass metabolism (10). The primary metabolites (norsibutramine and dinorsibutramine) are responsible for the activity and obstruct the reuptake of noradrenalin and serotonin (11). The acetylated sibutramine metabolite was detected in a patient's urine after consumption of an herbal slimming product (12).

Sibutramine inhibits noradrenaline and serotonin reuptake, which leads to developed satiety following reduction in food intake. According to random placebocontrolled studies (13-17), sibutramine alongside lifestyle and dietary advice can induce dose-dependent weight loss of $5 \%-10 \%$ in most patients $(18,19)$. Some studies have suggested that it increases serum high-density lipoprotein (HDL) cholesterol independently of weight loss (20).

The drug action may be boosted in mixture with other materials which increase the concentration of norepinephrine or serotonin in the synaptic cleft or which act as serotonin agonists because of structural similarities (21).

For these reasons, certain blends are in conflict with each other, mostly with several weight loss drugs, such as other SSRIs, MAO inhibitors, amphetamines, triptans, ergotamines, and some opioids (22).

Sibutramine has also been reported to have other severe side effects such as; panic attacks (23), memory impairment (24), psychotic episodes, increase in blood pressure and heart rate $(\mathrm{BP} / \mathrm{HR})(20-25)$. 
Severe weight loss can cause regression of left ventricular, congestive heart failure, cardiac arrhythmia, stroke, and uncontrolled hypertension (26). Therefore, it is necessary to recognize sibutramine and correlated compound in herbal products (27-29). Sibutramine was approved for a long term use in management of obesity in 1997. Nevertheless, due to the increased cardiovascular risk $(30,31)$, it was withdrawn from use within the European Union and in the United States.

The concomitant use of sibutramine and monoamine oxidase inhibitors (MAOIs, such as selegiline) has not been indicated, as it may increase the risk of serotonin syndrome. Moreover, the concomitant use of sibutramine and drugs which inhibit CYP3A4, such as ketoconazole and erythromycin, may increase plasma levels of sibutramine (27).

The incidental use of this drug could be an example of time-related incidence of adverse drug reactions (ADRs) or the adverse reaction might induce independently.

We have presented a patient, who developed ADRs differing in symptomatology due to the use of slimming product containing sibutramine as a major ingredient.

The aim of this study is to describe a case of acute poisoning with slimming capsule and review the available scientific literature.

\section{Case Presentation}

We describe a rare case of severe hyperpigmentation and tissue edema in an otherwise healthy 15 -year-old girl who took slimming herbal products containing sibutramine.

2.1. Case

In the presented case, a 15 years old healthy girl had bought a Chinese herbal medicine, entitled "Natural Max Slimming" via the Internet for weight reduction.

She was consumed this drug according to the instruction on the label. She took three capsules in a day, after consumption of 10 capsules she developed severe headaches, vertigo and numbness. The signs and symptoms increased gradually.

Two hours after the last dose (the 10th capsule), patient state got worsen and was admitted to a hospital. At first, patient had severe anxiety, hypertension, palpitation, confusion, chest pain, and was delirious.

At the beginning, patient level of conscious was G1; blood pressure was 140/80 mmHg, PR: 124 (beats/minute), RR: 22 with no fever. Pupils of two sides were dilated and symmetry but reflected to light.

On skin examination, the patient had severe hyper pigmentation especially in both lower extremities with tissue edema.
In neurological examinations there were hyperreflexia in deep tendon reflex and Babinski sign was detected bilaterally.

Tachycardia is indicated on an ECG, but dysrhythmia or block was not discovered. Patient's $\mathrm{O}_{2}$ saturation was $90 \%$ with respiratory alkalosis.

The patient chief complains were headache and vertigo responded to sedative prescription (5 mg midazolam).

In clinical laboratory examination, hematology, liver, kidney function test, and blood clotting tests were within normal limit.

The Creatine phosphokinase (CPK) level at admit time was $980(\mathrm{U} / \mathrm{L})$ and gradually increased to $1680(\mathrm{U} / \mathrm{L})$. After therapeutic support, the level decreased to near normal range.

The patient had auditory hallucination on and off and subsequently, developed persecutory delusions with depressed mood.

The patient was shortly disorientated to time and place and had chaotic motor activity. The next day she did not remember the previous night behaviors.

During the next four days in hospital, the auditory hallucination gradually disappeared and patient was discharged in good condition.

Even though, patient had spent 34 hours in ICU ward and all the necessary treatments and care were performed none the less, she was still suffering from skin discoloration and swelling of lower extremities (Figure 1).

The patient was followed up on regular bases in the following month after she was discharged and the results of routine laboratory tests, brain CT, ECG, and EEG revealed no abnormalities.

Approximately, after one month skin hyperpigmentation and edema was resolved and patient's situation completely returned back to normal state.

\section{Discussion}

The defined components in these Chinese prepared capsules are; sibutramine, a synthetic noradrenaline, dopamine, and serotonin reuptake inhibitor. Several conflicts use of sibutramine along with side effects caused by this drug is known which has resulted in obligatory medicinal control during its ingestion (28).

One of the problems usually encountered when using sibutramine is cardiovascular disorders, where it can substantially raise blood pressure and/or pulse rate and therefore, enhance acute heart failure.

Moreover, sibutramine can have side effects on the central nervous system like; headache, numbness, and paraesthesia $(28,29,32)$. 


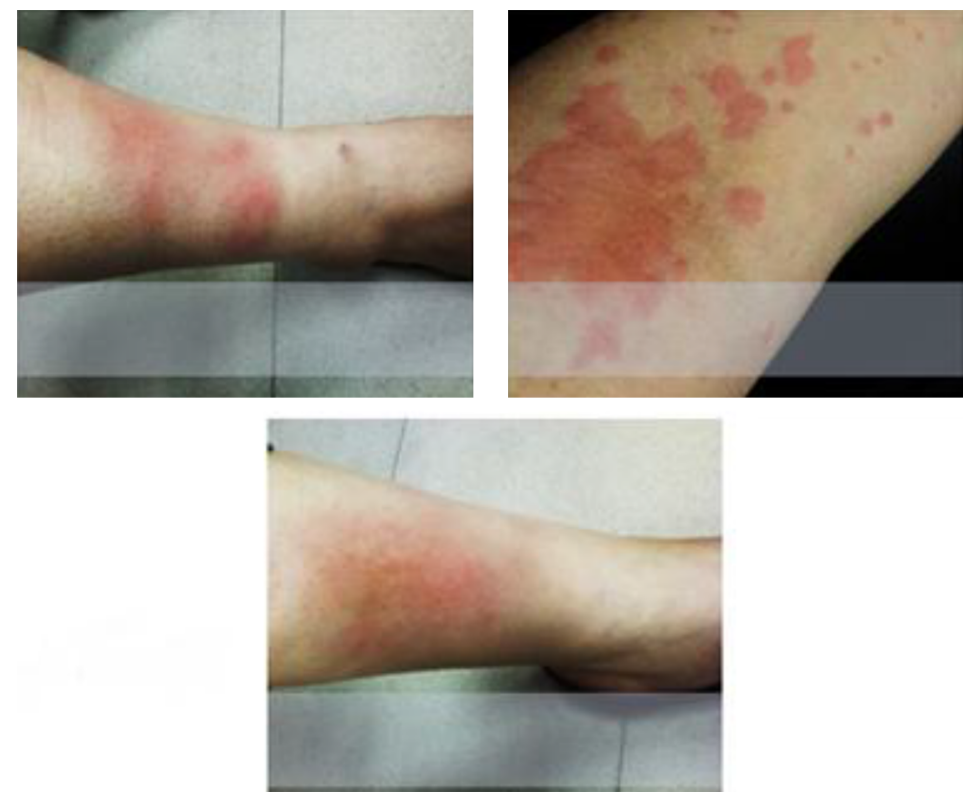

Figure 1. Hyperpigmentation After 34 Hours of Admission and During Discharge

Other side effects on alimentary system like xerostomia, nausea and constipation (33) were also reported in the literature.

According to the study of Florentin et al. an acute psychotic episode was reported after 3 to 7 months of sibutramine therapy. The symptoms gradually disappeared after drug discontinuation as well as the usage of antipsychotic medication such as risperidone and perazine (34).

The mechanism of sibutramine-induced acute coronary syndrome has not been established, but sibutramine may behave like amphetamine or amphetamine-like substance via reversible coronary narrowing or vasospasm.

The producers do not recommend prescribing sibutramine to patients with a history of coronary artery disease, congestive heart failure, arrhythmias, or stroke (33, 34).

Laboratory studies have suggested that sibutramine's action may be partially inhibited by noradrenergic antagonists (alpha and beta blockers) or serotonergic antagonists $(35,36)$.

In a recent report from a young Malaysian woman, acute myocardial infarction had occurred after 3 months of sibutramine consumption (37).

In this case, our patient had taken the medication for only 4 days and produced sibutramine induced skin hyperpigmentation and was in a confusional state.

Despite the fact that sibutramine was removed from the market in 2010, it is still being used in some countries as a dietary supplement in the black market or in slimming products. So, specific caution for sibutramine associated ADRs is still of prime importance and concern mostly in association with z-drugs which are being commonly prescribed and misused.

Therefore, powerful rules on the control of traditional herbal medicines are needed, involving certifying, tagging rules and value control mechanisms to prove components. Moreover, clinicians at poisoning wards must keep in mind that adulteration of herbal medicines may became more common and they should therefore, be considered, especially in cases where patients show confusing symptoms after ingestion of herbal medicines (38).

\subsection{Conclusions}

FDA has identified an emerging trend where over-thecounter products, frequently represented as dietary supplements, contain hidden active ingredients that could be harmful.

Consumers may unknowingly take products laced with varying quantities of approved prescription drug ingredients, controlled substances, and untested and unstudied pharmaceutically active ingredients. These deceptive products can harm you and create problems like this case. 


\section{Acknowledgments}

Authors would like to acknowledge Ali Asghar hospital poisoning ward medical teams for their helps and the kind support of research and consultation center http://research.sums.ac.ir, Shiraz University of Medical Sciences, Shiraz, Iran.

\section{Footnote}

Authors' Contribution: Fazel Goudarzi: study concept and design of the manuscript, Nahid Najafi: Acquisition of data, interpretation of case situation, drafting of the manuscript, Fazel Goudarzi and Negar Azarpira: critical revision of the manuscript for important intellectual content, Negar Azarpira: Study supervision, Nasim Tavakoli: editing of manuscript, Nasim Tavakoli and Zohre Najafi: association in drafting of the manuscript and interpretation of case situation.

\section{References}

1. Yuen YP, Lai CK, Poon WT, Ng SW, Chan AY, Mak TW. Adulteration of over-the-counter slimming products with pharmaceutical analoguean emerging threat. Hong Kong Med J. 2007;13(3):216-20. [PubMed: 17548910].

2. Tang MH, Chen SP, Ng SW, Chan AY, Mak TW. Case series on a diversity of illicit weight-reducing agents: from the well known to the unexpected. Br J Clin Pharmacol. 2011;71(2):250-3. doi: 10.1111/j.13652125.2010.03822.x. [PubMed: 21219406].

3. Spring S. Public Notification: Natural Max Slimming contains hidden drug ingredients 2015. Available from: http://www.fda.gov/Drugs/ ResourcesForYou/Consumers/BuyingUsingMedicineSafely/ MedicationHealthFraud/ucm436438.htm.

4. FDA . Slim Forte Slimming Capsule and Slim Forte Double Power Slimming Capsules: Public Notification - Undeclared Drug Ingredient 2011. Available from: http://www.drugs.com/fda/slim-forteslimming-capsule-slim-forte-double-power-slimming-capsulespublic-notification-12997.html.

5. FDA . Four Products Marketed as Weight Loss Supplements Contain Hidden Ingredients, FDA Warns. Over the counter and FDA 2015. Available from: https://www.nabp.net/news/four-products-marketed-asweight-loss-supplements-contain-hidden-ingredients-fda-warns.

6. FDA . SLIMDIA Revolution: Public Notification - Contains Undeclared Drug Ingredient Sibutramine 2012. Available from: http://www.drugs.com/fda/slimdia-revolution-public-notificationcontains-undeclared-ingredient-sibutramine-13224.html.

7. Jung J, Hermanns-Clausen M, Weinmann W. Anorectic sibutramine detected in a Chinese herbal drug for weight loss. Forensic Sci Int. 2006;161(2-3):221-2. doi: 10.1016/j.forsciint.2006.02.052. [PubMed: 16870382].

8. Link M, Hakala KS, Wsol V, Kostiainen R, Ketola RA. Metabolite profile of sibutramine in human urine: a liquid chromatographyelectrospray ionization mass spectrometric study. J Mass Spectrom. 2006;41(9):1171-8. doi: 10.1002/jms.1082. [PubMed: 16888717]

9. Luque CA, Rey JA. Sibutramine: a serotonin-norepinephrine reuptake-inhibitor for the treatment of obesity. Ann Pharmacother. 1999;33(9):968-78. [PubMed:10492502].
10. Muller D, Weinmann W, Hermanns-Clausen M. Chinese slimming capsules containing sibutramine sold over the Internet: a case series. Dtsch Arztebl Int. 2009;106(13):218-22. doi: 10.3238/arztebl.2009.0218. [PubMed: 19471631].

11. Vidal C, Quandte S. Identification of a sibutramine-metabolite in patient urine after intake of a "pure herbal" Chinese slimming product. Ther Drug Monit. 2006;28(5):690-2. doi: 10.1097/01.ftd.0000245392.33305.bo. [PubMed: 17038887].

12. James WP, Astrup A, Finer N, Hilsted J, Kopelman P, Rossner S, et al. Effect of sibutramine on weight maintenance after weight loss: a randomised trial. STORM Study Group. Sibutramine Trial of Obesity Reduction and Maintenance. Lancet. 2000;356(9248):2119-25. [PubMed: 11191537].

13. Wirth A, Krause J. Long-term weight loss with sibutramine: a randomized controlled trial. JAMA. 2001;286(11):1331-9. [PubMed: 11560538].

14. Finer N, Bloom SR, Frost GS, Banks LM, Griffiths J. Sibutramine is effective for weight loss and diabetic control in obesity with type $2 \mathrm{di}$ abetes: a randomised, double-blind, placebo-controlled study. Diabetes Obes Metab. 2000;2(2):105-12. [PubMed:11220522].

15. McNulty SJ, Ur E, Williams G, Multicenter Sibutramine Study G. A randomized trial of sibutramine in the management of obese type 2 diabetic patients treated with metformin. Diabetes Care. 2003;26(1):12531. [PubMed: 12502668].

16. Nisoli E, Carruba MO. An assessment of the safety and efficacy of sibutramine, an anti-obesity drug with a novel mechanism of action. Obes Rev. 2000;1(2):127-39. [PubMed:12119986].

17. Taflinski T, Chojnacka J. Sibutramine-associated psychotic episode. Am J Psychiatry. 2000;157(12):2057-8. [PubMed: 11097984].

18. Binkley K, Knowles SR. Sibutramine and panic attacks. Am J Psychiatry. 2002;159(10):1793-4. [PubMed: 12359693].

19. Clark DW, Harrison-Woolrych M. Sibutramine may be associated with memory impairment. BMJ. 2004;329(7478):1316. doi: 10.1136/bmj.329.7478.1316. [PubMed: 15576742].

20. Padwal RS, Majumdar SR. Drug treatments for obesity: orlistat, sibutramine, and rimonabant. Lancet. 2007;369(9555):71-7. doi 10.1016/S0140-6736(07)60033-6. [PubMed: 17208644].

21. Zannad F, Gille B, Grentzinger A, Bruntz JF, Hammadi M, Boivin $\mathrm{JM}$, et al. Effects of sibutramine on ventricular dimensions and heart valves in obese patients during weight reduction. Am Heart J. 2002;144(3):508-15. [PubMed: 12228789].

22. Gratz SR, Gamble BM, Flurer RA. Accurate mass measurement using Fourier transform ion cyclotron resonance mass spectrometry for structure elucidation of designer drug analogs of tadalafil, vardenafil and sildenafil in herbal and pharmaceutical matrices. Rapid Commun Mass Spectrom. 2006;20(15):2317-27. doi: 10.1002/rcm.2594. [PubMed: 16817245].

23. Zou P, Oh SS, Hou P, Low MY, Koh HL. Simultaneous determination of synthetic phosphodiesterase- 5 inhibitors found in a dietary supplement and pre-mixed bulk powders for dietary supplements using high-performance liquid chromatography with diode array detection and liquid chromatography-electrospray ionization tandem mass spectrometry. J Chromatogr A. 2006;1104(1-2):113-22. doi: 10.1016/j.chroma.2005.11.103. [PubMed: 16364350].

24. Cheng HL, Tseng MC, Tsai PL, Her GR. Analysis of synthetic chemical drugs in adulterated Chinese medicines by capillary electrophoresis/electrospray ionization mass spectrometry. Rapid Commun Mass Spectrom. 2001;15(16):1473-80. doi: 10.1002/rcm.396. [PubMed: 11507761].

25. James WP, Caterson ID, Coutinho W, Finer N, Van Gaal LF, Maggioni AP, et al. Effect of sibutramine on cardiovascular outcomes in overweight and obese subjects. N Engl J Med. 2010;363(10):905-17. doi:10.1056/NEJMoa1003114. [PubMed: 20818901].

26. Scheen AJ. Sibutramine on cardiovascular outcome. Diabetes Care. 2011;34 Suppl 2:S114-9. doi: 10.2337/dc11-s205. [PubMed: 21525441].

27. Mathys M. Drug Interactions Associated with the Use of Antidepressant Medications. Internet Continu Educ. 2005;9(3):1-15. 
28. Altabas V. Drug treatment of metabolic syndrome. Curr Clin Pharmacol. 2013;8(3):224-31. [PubMed: 22950955].

29. Wong AH, Barg SS, Leung AK. Pharmacotherapy for Obesity. Recent Patents Endocr Metabol Immune Drug Discover. 2010;4(1):47-58.

30. Misra A, Chowbey P, Makkar BM, Vikram NK, Wasir JS, Chadha D, et al. Consensus statement for diagnosis of obesity, abdominal obesity and the metabolic syndrome for Asian Indians and recommendations for physical activity, medical and surgical management.JAssoc Physicians India. 2009;57:163-70. [PubMed: 19582986].

31. Wooltorton E. Obesity drug sibutramine (Meridia): hypertension and cardiac arrhythmias. CMAJ. 2002;166(10):1307-8. [PubMed: 12041851].

32. Wiglusz MS, Cubala WJ, Nowak P, Jakuszkowiak-Wojten K, Landowski J, Krysta K. Sibutramine-associated psychotic symptoms and zolpidem-induced complex behaviours: implications for patient safety. Psychiatr Danub. 2013;25 Suppl 2:S143-5. [PubMed: 23995163].

33. Karam JG, McFarlane SI. Tackling obesity: new therapeutic agents for assisted weight loss. Diabetes Metabolic Syndrome Obes Targets Ther.
2010;3:95

34. Florentin M, Liberopoulos EN, Elisaf MS. Sibutramine-associated adverse effects: a practical guide for its safe use. Obes Rev. 2008;9(4):37887. doi: 10.1111/j.1467-789X.2007.00425.x. [PubMed: 18034790].

35. Bray GA, Ryan DH, Gordon D, Heidingsfelder S, Cerise F, Wilson K. A double-blind randomized placebo-controlled trial of sibutramine. Obes Res. 1996;4(3):263-70. [PubMed: 8732960].

36. McNeely W, Goa KL. Sibutramine. A review of its contribution to the management of obesity. Drugs. 1998;56(6):1093-124. [PubMed: 9878996].

37. Azarisman SM, Magdi YA, Noorfaizan S, Oteh M. Myocardial infarction induced by appetite suppressants in Malaysia. $N$ Engl J Med. 2007;357(18):1873-4. doi:10.1056/NEJMc070990. [PubMed: 17978302].

38. Koh HL, Woo SO. Chinese proprietary medicine in Singapore: regulatory control of toxic heavy metals and undeclared drugs. Drug Saf. 2000;23(5):351-62. [PubMed: 11085343]. 